\title{
Phospholipid binding specificities and idiotype expression of hybridoma derived monoclonal autoantibodies from splenic cells of patients with systemic lupus erythematosus
}

C T Ravirajan, Ian Harmer, Tracy McNally, A Hohmann, C G Mackworth-Young, D A Isenberg

\begin{abstract}
Objective-To analyse the phospholipid binding specificity, functional characteristics and idiotype expression of human hybridoma derived monoclonal autoantibodies (MAb) derived from the spleens of two patients with active systemic lupus erythematosus (SLE).

Methods-The IgM MAbs binding to phospholipids were generated from spleen cells of two patients (RSP and RT) with active SLE and their specificity of binding to neutral phospholipids (phosphatidyl ethanolamine, phosphatidyl choline, platelet activating factor, sphingomyelin) and negatively charged phospholipids (phosphatidyl glycerol, phosphatidyl serine, phosphatidic acid, phosphatidyl inositol and cardiolipin (CL)) analysed. Binding specificity of cross reactive antibodies (those binding to CL and DNA) was confirmed by fluid phase inhibition assays. Lupus anticoagulant activity and $\beta_{2}$-glycoprotein-1 $\left(\beta_{2}\right.$ GP-1) requirement for the antigen binding of these MAbs were detected using the modified dilute Russell's viper venom test and modified anti-CL enzyme linked immunosorbent assay (ELISA), respectively. Expression of idiotypes (Id) Id RT-84 and Id H3 was analysed using rabbit polyclonal and murine monoclonal anti-idiotype reagents, respectively.
\end{abstract}

Results-Twelve clones from the patient RSP and eight clones from patient RT were reactive with phospholipids. Marked differences in phospholipid binding of these MAbs were noted, varying from truly polyreactive (RT-72 bound to most phospholipids tested) to monospecific (RT-84 bound only to CL). Furthermore, MAbs RT-84, RT-129, and RSP-57 had lupus anticoagulant activity and required $\beta_{2}$ GP-1 for CL binding. It was found that $75 \%$ of phospholipid binding antibodies from RT clones expressed RT-84 Id, but none from RSP clones did so, and that Id H3 was expressed only by the RT-83 antibody.

Conclusion-These results show that human anti-phospholipid MAbs are heterogeneous with respect to phospho- lipid binding, functional characteristics, and Id expression.

(Ann Rheum Dis 1995; 54: 471-476)

Systemic lupus erythematosus (SLE) is an autoimmune rheumatic disease characterised serologically by the presence of a variety of autoantibodies. Antiphospholipid (aPL) antibodies are associated with a clotting tendency and recurrent fetal loss in a subset of SLE patients. ${ }^{1-5}$ aPL antibodies can be detected in plasma or serum by solid phase immunoassays in which negatively charged phospholipids, most commonly cardiolipin (CL), are used as the antigen. ${ }^{6-9}$ The question if the sera of individuals with aPL antibodies contain a multiplicity of antibodies with different monospecific reactivities, or if the antibodies from these individuals are polyreactive has not been addressed in studies of MAbs derived from hybridomas obtained from human tissues. Limitations in the production of human hybridoma derived phospholipid binding MAbs from SLE patients have restricted such studies in humans. We reported a detailed analysis of the antigen binding profile of 19 human MAbs from a selection of 245 clones derived from the spleens of two patients with SLE. ${ }^{10}$ We have now extended this study and analysed the binding specificity of these aPL antibodies to a variety of negatively charged and neutral phospholipids, and examined their functional effects in anticoagulation assays.

Three independent groups have reported that the CL binding of anti-CL (aCL) antibodies in the sera from patients with SLE was dependent on the presence of the $50 \mathrm{kDa}$ serum glycoprotein, $\beta_{2}$-glycoprotein-1 $\left(\beta_{2^{-}}\right.$ GP-1) (aCL cofactor). ${ }^{11-13}$ aCL antibodies found in the sera of patients with various infectious diseases bound to $\mathrm{CL}$ without $\beta_{2}-G P-1 .^{14}$ We have confirmed the $\beta_{2}-$ GP-1 requirement of these $\mathrm{MAb}$ for the $\mathrm{CL}$ binding in a modified CL binding enzyme linked immunosorbent assay (ELISA). The expression of idiotypes (Id) RT-84 and H3, which are commonly expressed in the sera of patients with SLE, was also analysed in these aPL antibodies. 


\section{Materials and methods}

HUMAN SPLEEN CELLS

Cells were obtained from the spleens of a 13 year old girl $(\mathrm{T})$ and 29 year old woman (SP), both with active SLE and both of whom required splenectomy for severe thrombocytopenia.

HUMAN HYBRIDOMA FUSION

The hybridomas were produced from the spleen cells of SLE patients using the human lymphoblastoid cell line GM4672 (Cell Repository, Institute of Medical Research, Camden, NJ) as the fusion partner. Generation and characterisation of RSP and RT MAbs were described in detail in our previous paper. $^{10}$

PURIFICATION OF IgM MONOCLONAL ANTIBODIES

Culture supernatants were centrifuged to remove cells and concentrated using a stirred cell concentrator and YM30 membrane (Amicon, Stonehouse, Glos). Monoclonal antibodies were purified from the concentrate on a goat antihuman IgM-Sepharose 4B affinity column (Pharmacia, Milton Keynes, Bucks) and the eluate reconcentrated using the cell concentrator.

ANTIPHOSPHOLIPID ANTIBODY DETECTION

We used the direct binding ELISA described by Loizou $e t a l^{6}$ to determine the reactivity of MAbs to CL, phosphatidyl choline (PC), phosphatidyl ethanolamine (PE), sphingomyelin (SM), platelet activating factor (PAF), phosphatidyl glycerol (PG), phosphatidyl serine (PS), phosphatidic acid (PA), and phosphatidyl inositol (PI) (Sigma, approximate purity $95-99 \%$ ). Briefly, half the plate was coated with phospholipids $(100 \mu \mathrm{g} / \mathrm{ml})$ in ethanol (Sigma) while the other half was incubated with ethanol alone and evaporated overnight at $4^{\circ} \mathrm{C}$. Plates were blocked with $10 \%$ fetal calf serum (FCS) in phosphate buffered saline (PBS) for two hours at room temperature, then washed in PBS. Culture supernatants from hybridoma clones were diluted in $10 \%$ FCS in PBS and incubated for two hours at room temperature. The plates were washed three times with PBS and goat antihuman IgM alkaline phosphatase conjugate (Sigma) at a dilution of 1:1000 was added, followed by substrate (paranitrophenyl phosphate (Sigma) at $1 \mathrm{mg} / \mathrm{ml}$ in carbonate

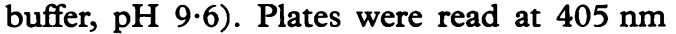
using a Dynatech MR4000 ELISA plate reader. Final optical density (OD) values were determined by subtracting the mean of triplicate readings obtained in the uncoated half of the plate from the corresponding mean values obtained when the plates were coated with antigens. Reactivity of the MAbs (OD values) to each of the antigens was graded: $O D$ value $0-0 \cdot 2=-; 0 \cdot 21-0.4=+/-$; $0.41-0.06=+; \quad 0.61-0.8=++; \quad 0.81$ and greater $=+++$.
MODIFIED CARDIOLIPIN BINDING ASSAY

The standard phospholipid ELISA described above was modified as follows. Skimmed milk powder ( $1 \%$ ) (Tesco stores Ltd, Herts)/0.3\% gelatin (Sigma)/PBS was used for the blocking step. Affinity purified MAbs were diluted in $0.3 \%$ gelatine/PBS, and antihuman IgM alkaline phosphatase conjugate was diluted in $1 \%$ BSA (Sigma)/PBS instead of $10 \%$ FCS. Other details remained as described above.

ANTIGEN COMPETITIVE INHIBITION ASSAY

The concentration of $\mathrm{MAb}$ giving $70 \%$ maximum binding to various phospholipids (CL, PS, PI, and PC) in the direct binding ELISA was established. Equal volumes of MAbs and a range of concentrations of inhibitors from 1 to $100 \mu \mathrm{g} / \mathrm{ml}$ were incubated together for two hours at room temperature and transferred to the wells of phospholipid coated plates. Single and double stranded DNA (calf thymus, Sigma), CL, PS, PC, and PI in PBS emulsion were used as inhibitors. The assays were completed as for the direct binding ELISA.

PRODUCTION AND PURIFICATION OF ANTIIDIOTYPE RT-84

A New Zealand white rabbit was immunised by multiple intradermal injection with a total dose of $100 \mu \mathrm{g}$ affinity purified MAb RT-84 emulsified in incomplete Freund's adjuvant. A control rabbit received only adjuvant. Booster doses of immunogen in incomplete Freund's adjuvant were given on days 30 and 40 . Sera were obtained on day 55 and tested for reactivity against MAb RT-84 and human IgM in a direct binding ELISA.

Polyclonal anti-Id serum was rendered Id specific by repeated passage through an immunoaffinity absorbent column containing pooled human Ig linked to Sepharose 4B and further positive purification on an RT-84 MAb-Sepharose $4 \mathrm{~B}$ column, eluting the bound anti-Id antibodies with $0.1 \mathrm{~mol} / \mathrm{l}$ glycine hydrochloride $(\mathrm{pH} 2 \cdot 3)$. The rabbit anti-Id reagent was shown to be Id specific using a direct binding ELISA. ${ }^{16}$

\section{DETECTION OF LUPUS ANTICOAGULANT} ACTIVITY

The ability of MAbs to prolong phospholipid coagulation tests (lupus anticoagulant activity) was determined using the modified dilute Russell's viper venom time test (DRVVT).${ }^{17}$ In brief, $0.1 \mathrm{ml}$ of the cell culture supernatant, or RPMI, was mixed with $0.1 \mathrm{ml}$ normal plasma and $0.1 \mathrm{ml}$ dilute phospholipid reagent (or freeze-thawed platelets); $0 \cdot 1 \mathrm{ml}$ Russell's viper venom was added and after incubation for 30 seconds clotting was initiated by the addition of $0.1 \mathrm{ml} 0.025 \mathrm{~mol} / 1$ calcium chloride. The presence of lupus anticoagulant activity was characterised by a ratio of test to control clotting time of $>1 \cdot 1$, which should decrease by greater than $10 \%$ or to within normal limits 
when freezed-thawed platelets are used instead of the phospholipid reagent.

DETECTION OF IDIOTYPE RT-84

Half the wells of the immunoplates were coated with rabbit anti-RT-84 Id $(2.5 \mu \mathrm{g} / \mathrm{ml})$ overnight at $4^{\circ} \mathrm{C}$ and the remaining wells were coated with immunoglobulins (Ig) purified from control rabbit sera, at an equal concentration. Non-specific binding was blocked with $2 \% \mathrm{BSA}$ in bicarbonate buffer. Samples of human sera at a dilution of 1:100 in PBS-Tween-1\% BSA were added in duplicate to wells in both halves of the plate and incubated for one hour at $37^{\circ} \mathrm{C}$. Bound human Ig was detected using goat anti-human IgM $\mathrm{Fab}_{2}$ alkaline phosphatase conjugate (1:500) (Sigma) followed by addition of substrate $(1 \mathrm{mg} / \mathrm{ml}$ di-nitrophenyl phosphate (Sigma)) in carbonate buffer, $\mathrm{pH} 9 \cdot 6$. Plates were read at $405 \mathrm{~nm}$ using a Dynatech MR4000 ELISA plate reader. The OD values obtained on the rabbit IgG control side were subtracted from those obtained on the anti-Id side.

DETECTION OF THE H3 IDIOTYPE

ELISA plates were coated with purified Ig preparations of the mouse monoclonal anti-H3 Id, $\mathrm{S} 2.9^{18}$ or a negative control FMC8; ${ }^{19}$ both are IgG2b class antibodies. Coating was achieved overnight at $4^{\circ} \mathrm{C}$ at a concentration of $2 \mu \mathrm{g} / \mathrm{ml}$. Culture supernatants from the human hybridomas were applied to these plates and the binding of human IgM detected with alkaline phosphatase labelled anti-human IgM (Silenus, Hawthorn, Victoria). H3, a human hybridoma antibody reacting with $\mathrm{CL}^{20}$ was used as a positive control. This IgM carries an SLE associated idiotype defined by the $\$ 2.9$ monoclonal antibody. ${ }^{18}$

\section{Results}

The frequency of clones obtained from two human-human hybridoma fusion experiments, RSP and RT, and the nature of the immunoglobulins secreted by those clones have been described elsewhere. ${ }^{10}$ Monoclonal antibodies from both fusions bound to negatively charged (PA, PI, PG, PS and CL) and neutral (PE, PC, PAF and SM) phospholipids (table 1). Some MAbs bound to all the phospholipid antigens (for example RT-72), whereas others reacted with a restricted number of phospholipids (for example RT-84). Monoclonal antibodies RT-84, RT-129, RT-79, RT-72, and RT-115 had previously been shown to react with either ssDNA or dsDNA in addition to CL. ${ }^{10}$

Figure 1 shows representative examples of the direct phospholipid binding profiles of the MAbs which were confirmed by the fluid phase inhibition assays.

Binding of RT MAbs to CL in the ELISA was not affected (fig 2) when these antibodies were preincubated with either ssDNA or dsDNA in the fluid phase. The same was true for RSP MAbs which did not react with ssDNA or dsDNA in the direct binding ELISA.

The affinity purified MAbs RT-84, RT-129 and RSP-57 all bound poorly to CL in the modified aCL ELISA (fig 3). However, when $10 \%$ FCS was used as diluent of antibodies, all three purified MAbs bound to CL.

When the functional characteristics of these antibodies were analysed using phospholipid DRVVT and platelet DRVVT, three MAbs, RT-84, RT-129 and RSP-57, were found to have lupus anticoagulant activity (table 2).

With the exception of RT-83 and RT-72, all the other phospholipid binding antibodies (75\%) derived from the RT fusion expressed the RT-84 Id, which was originally identified on MAb RT-84. In contrast, none of the RSP antibodies expressed Id RT-84. The antibodies screened with the mouse monoclonal anti-H3 Id antibody (S2.9) failed to show any binding above background, except for RT-83 for which the OD value of 1.65 , compared with the background of 0.05 , was regarded as positive. In the same assay, $\mathrm{H} 3$ positive control gave an OD of 1.26 against the background control of 0.05 .

\section{Discussion}

In our previous paper ${ }^{10}$ we demonstrated that the antigen binding specificity of two sets of MAbs (RT and RSP) reflected the serum antibody specificity of those patients from whom the spleens were obtained. Briefly the serological profile of patient RSP (weak positive ANA, negative anti-dsDNA, strong positive aCL antibody) was reflected in the clones derived from her splenic lymphocytes as, in those clones (RSP), aPL antibody producers were relatively common, but none bound to DNA. In contrast, the antibodies derived from patient RT bound to nuclear

Table 1 Phospholipid binding specificities of some selected monoclonal autoantibodies from RT and RSP fusions

\begin{tabular}{|c|c|c|c|c|c|c|c|c|c|c|c|c|c|}
\hline \multirow[t]{2}{*}{ Phospholipids } & \multicolumn{13}{|c|}{ Human hybridoma derived monoclonal antibodies } \\
\hline & $R T-16$ & $R T-55$ & $R T-72$ & $R T-79$ & $R T-83$ & $R T-84$ & $R T-115$ & $R T-129$ & $R S P-3$ & $R S P-6$ & $R S P-13$ & $R S P-18$ & RSP-57 \\
\hline \multicolumn{14}{|l|}{ Neutral } \\
\hline Phosphatidyl ethanolamine & - & - & +++ & - & - & - & - & - & - & - & - & - & - \\
\hline Phosphatidyl choline & + & - & +++ & + & - & - & + & + & - & + & - & - & - \\
\hline Platelet activating factor & - & - & + & - & - & - & - & - & - & + & - & - & - \\
\hline Sphingomyelin & - & + & + & + & - & - & + & - & - & - & - & - & - \\
\hline \multicolumn{14}{|l|}{ Negatively charged } \\
\hline Phosphatidyl glycerol & + & - & - & - & + & - & - & - & + & ++ & + & ++ & + \\
\hline Phosphatidyl serine & - & - & + & - & - & - & - & - & + & ++ & - & + & - \\
\hline Phosphatidic acid & - & - & + & + & - & - & - & - & + & ++ & - & ++ & + \\
\hline Phosphatidyl inositol & + & - & ++ & - & + & - & - & - & + & ++ & - & ++ & + \\
\hline Cardiolipin & - & - & ++ & + & $+1-$ & ++ & + & + & ++ & +++ & +++ & +++ & +++ \\
\hline
\end{tabular}



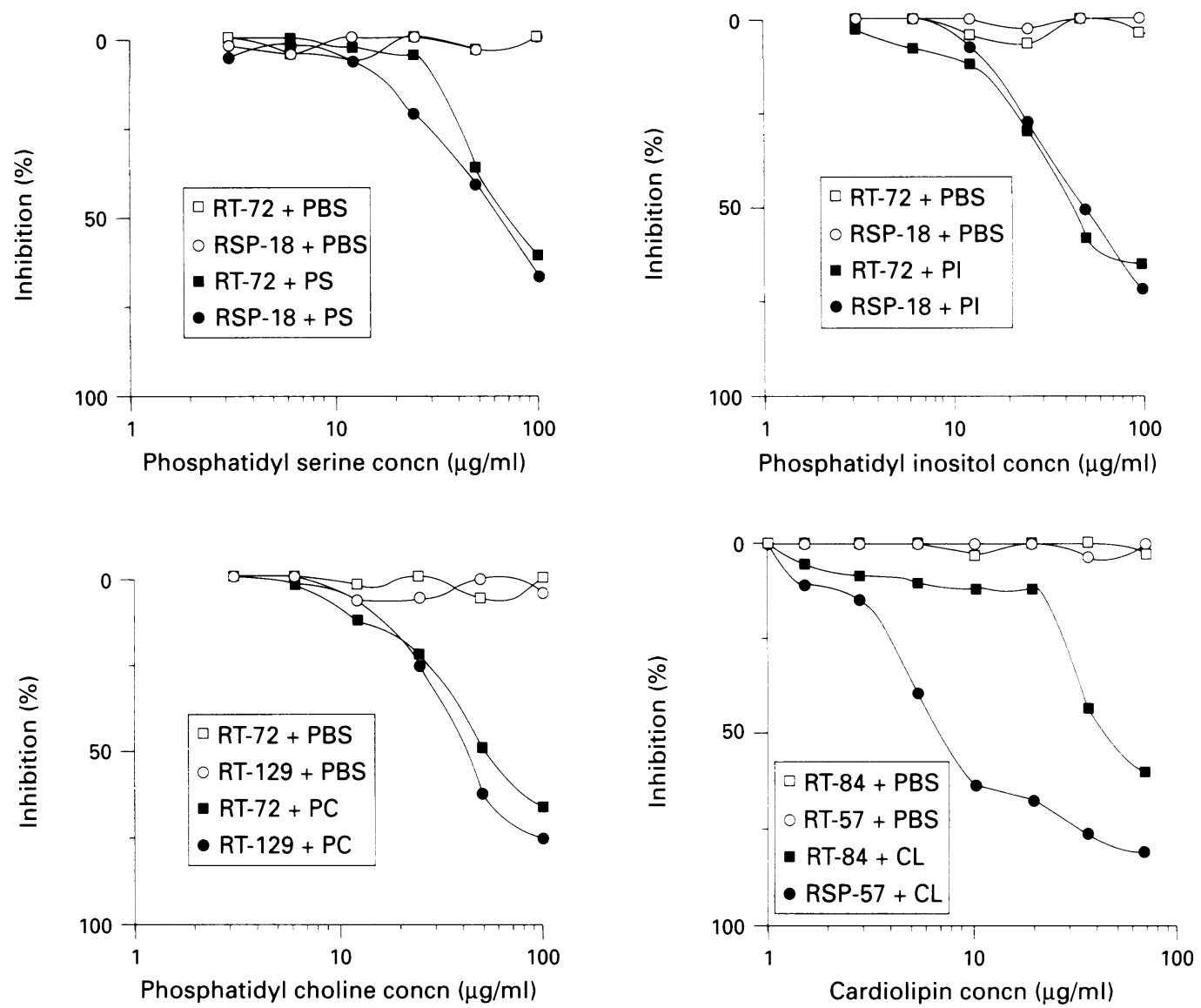

Figure 1 Inhibition of monoclonal antibodies by phospholipids in the fluid phase antigen inhibition assay. RT-57, RT-72, $R T-84, R T-129, R S P-18, R S P-57=$ monoclonal antibodies of patients $T$ and $S P ; P B S=$ phosphate buffered saline; $P S=$ phosphatidyl serine $P C=$ phosphatidyl choline; $P I=$ phosphatidyl inositol; $C L=$ cardiolipin .

components and phospholipids and the same profile was found in her serum. In this study we have further analysed the fine specificity of phospholipid binding, and the functional characteristics and Id expression of the two sets of aPL antibodies.

These antibodies are mainly of the $\operatorname{IgM}$ isotype and many IgMs produced from human tissues are polyreactive immunoglobulins. ${ }^{21} 22$ Although some of the $\operatorname{IgM}$ antibodies described do react with several phospholipids (table 1), what is far more impressive is the restriction observed in the antibody binding profiles. Thus some monoclonals (for example

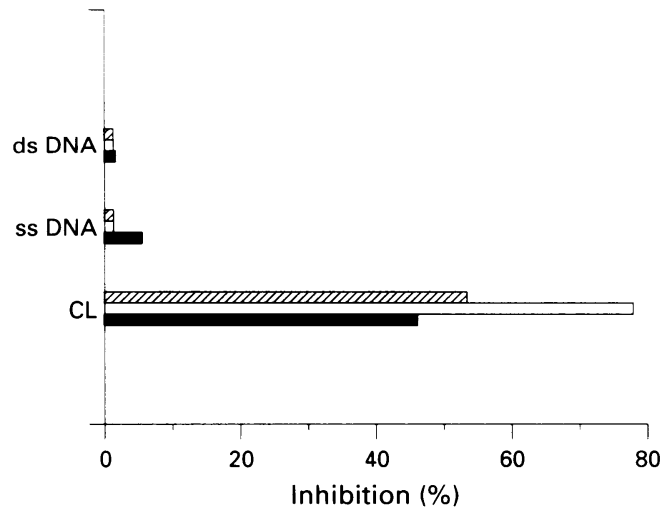

Figure 2 Competitive inhibition assay. Binding of human monoclonal antibodies RT-84 ( $\square$ ), RSP-57 ( $\square$ ), and $R T-72(\mathbb{Z})$ to cardiolipin attached to the plate was inhibited by $50 \mu \mathrm{g} / \mathrm{ml}$ cardiolipin (CL) but not by $50 \mu \mathrm{g} / \mathrm{ml}$ $s s D N A$ or $d s D N A$ in the fluid phase.
RT-84, RT-55) recognised a single phospholipid antigen, others (RT-16, RT-129) recognised just two or three, while a third group of antibodies (RT-72, RSP-6) bound to most of the phospholipid antigens.

Studies using an array of phospholipid antigens have shown that autoantibodies in patient sera are serologically polymorphic. ${ }^{23} 24$ In the present study using several hybridoma derived human MAbs, we have shown that human phospholipid binding MAbs are also serologically polymorphic with respect to their

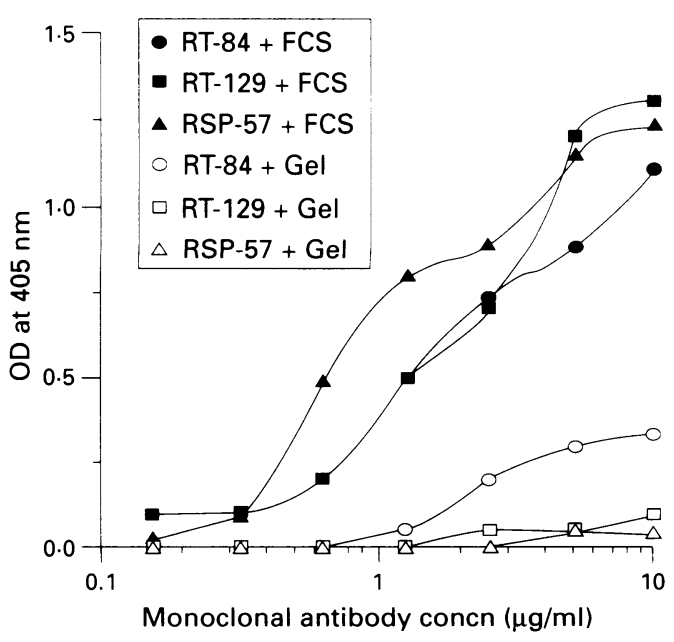

Figure 3 Binding of monoclonal antibodies (RT-84, RT-129, RSP-57) to cardiolipin in the presence and absence of fetal calf serum (FCS), assayed by standard and modified cardiolipin ELISAs. Gel = Gelatine; $O D=$ optical density. 
Table 2 Lupus anticoagulant activity of monoclonal antibodies $(M A b)$. RT-84, RT-129, and RSP-57 all demonstrated activity $(D R V V T$ ratio $>1 \cdot 1)$

\begin{tabular}{lll}
\hline$M A b$ & $\begin{array}{l}\text { Phospholipid DRVVT } \\
\text { ratio }\end{array}$ & $\begin{array}{l}\text { Platelet DRVVT } \\
\text { ratio }\end{array}$ \\
\hline RT-55 & 1.00 & NT \\
RT-72 & 1.06 & NT \\
RT-79 & 0.97 & NT \\
RT-83 & 1.03 & NT \\
RT-84 & 1.34 & 1.21 \\
RT-115 & 1.00 & NT \\
RT-129 & 1.39 & 1.22 \\
RSP-3 & 1.03 & NT \\
RSP-6 & 1.06 & NT \\
RSP-13 & 1.03 & NT \\
RSP-18 & 1.00 & NT \\
RSP-57 & 1.42 & 1.17 \\
\hline
\end{tabular}

DRVVT = Dilute Russell's viper venom test; NT = not tested.

capacity to react with a wide diversity of different phospholipids.

Antibodies binding to negatively charged or non-bilayer phospholipids are associated with the immunopathogenesis of autoimmune diseases such as $\mathrm{SLE}^{25-28}$ and antibodies binding only to neutral phospholipids are mostly detected in infectious diseases. ${ }^{29}$ Among our selection of antibodies, some bound only to negatively charged phospholipid antigens, including MAbs RT-84 and RSP-57 which bound to CL only or to CL, PI, PA, PS, and PG, respectively. Other MAbs reacted with both negatively charged and neutral phospholipid antigens: these antibodies may be recognising common epitopes on different phospholipids. This finding also excludes the possibility that IgM aPL antibodies bind nonspecifically to various charged molecules.

The modified CL binding ELISA showed a requirement for $10 \%$ FCS (a source of $\left.\beta_{2}-\mathrm{GP}-1\right)$ for the binding of purified MAbs RT-84, RT-129, and RSP-57 to CL in the solid phase. This suggests that these antibodies are representative of serum aCL antibodies from SLE patients which require the co-factor $\beta_{2}$-GP-1 for antigen binding. ${ }^{11-13}$

Most of the RT MAbs studied bound to both DNA and phospholipids. ${ }^{10}$ This type of IgM antiDNA antibody is regarded as being cross reactive, by binding non-specifically to charged molecules. Inhibition of antibody binding to phospholipids, attributable to phospholipids present in the fluid phase in the competitive inhibition assays, further confirmed the phospholipid binding specificity of these antibodies. However, in the cross antigen competitive inhibition assay, the DNA in the fluid phase did not affect the binding of these antibodies to CL. This finding suggests that the functional affinity of these antibodies to phospholipids is greater than that to DNA. Although all RSP antibodies but one bound exclusively to negatively charged phospholipids and most of the RT antibodies bound to both negatively and positively charged phospholipids, there was no marked difference between these two sets of antibodies regarding phospholipid binding.

The expression of lupus anticoagulant activity by the MAbs RT-84, RT-129, and RSP-57 emphasises the point that IgM aPL antibodies do not merely bind to phospho- lipids, but they also have functional anticoagulant properties.

We further analysed the expression of two Ids, Id RT-84 and Id H3, originally identified on MAbs RT-84 and H3, respectively. The H3 Id is defined by a mouse MAb S2.9. ${ }^{18}$ Among the selection of aPL antibodies we studied, one, MAb RT-83, expressed H3 Id. Interestingly, both MAbs $\mathrm{H} 3$ and RT-83 have IgM $\lambda$ light chains, suggesting that this is where H3 Id is likely to be located. H3 Id is commonly found in patients with SLE, in whom it is correlated with the amount of aCL antibodies. $^{30}$ No correlation between the amount of aCL antibody and H3 Id was found in patients with infective diseases (for example syphilis). Expression of Id $\mathrm{H} 3$ on a phospholipid binding $\mathrm{MAb}$ derived from another SLE patient further supports the view that this Id is related to SLE. RT-84 is a DNA binding antibody ${ }^{10}$ with aCL activity. Id RT-84 is defined by polyclonal rabbit anti-RT-84 sera and this Id is expressed in $40 \%$ of SLE patients. ${ }^{31}$ Using anti-RT-84 reagent, it was found that $75 \%$ of aPL antibodies from RT fusion expressed Id RT-84, but none from the RSP fusion did so. This finding suggests that, although these two sets of antibodies (RT and $\mathrm{RSP}$ ) bind to the phospholipid antigens, they differ in their idiotype markers.

1 Carreras L W, Difreyn G, Machin S J, et al. Arterial thrombosis, intrauterine death and 'lupus' anticoagulant: detection of immunoglobulin interfering with prostacyclin formation. Lancet 1981 ; i: 244-5.

2 Feinstein D I. Lupus anticoagulant, thrombosis, and fetal

loss. N Engl f Med 1985; 313: 1348-50.
3 Meroni P L, Rivolta R, Ghidoni P. Histopathological findings in a case of systemic lupus erythematosusassociated anti-phospholipid syndrome. Clin Rheumatol associated anti-pho

4 Leung W H, Wong K L, Lau C P, et al. Association between antiphospholipid antibodies and cardiac abnormalities in patients with systemic lupus erythematosus. $\mathrm{Am} \mathcal{F} \mathrm{Med}$ 1990; 89: 411-9.

5 Kalunian K C, Peter J B, Middlekauff H R, et al. Clinical significance of a single test for anti-cardiolipin antibodies in patients with systemic lupus erythematosus. $A m \mathcal{F} \mathrm{Med}$ 1988; 85: 602-8.

6 Loizou S, McCrea J D, Rudge A C, et al. Measurement of anti-cardiolipin antibodies by an enzyme-linked immunosorbent assay (ELISA): standardization and quantitation of results. Clin Exp Immunol 1985; 62: 738-45.

7 Harris E N, Gharavi A E, Boey M L, et al. Anticardiolipin antibodies: detection by radioimmunoassay and association with thrombosis in systemic lupus erythematosus. Lancet 1983; ii: 1211-2.

8 Koike T, Maruyama N, Funaki H, et al. Specificity of mouse hybridoma antibodies to DNA. II. Phospholipid reactivity and biological false positive serological test for syphilis. Clin Exp Immunol 1984; 57: 345-50

9 Brown R D, Gibson J, Wells J, et al. Human cardiolipin as the antigen in an ELISA to detect anticardiolipin antibodies. $\mathrm{Br} \mathcal{F}$ Rheum 1989; 28: 109-12.

10 Ravirajan C T, Kalsi J, Winska-Wiloch H, et al. Antigen binding diversity of human hybridoma derived autoantibodies from splenocytes of patients with SLE. Lupus antibodies from

11 Matsuura E, Igarashi Y, Fujlmolo M, et al. Heterogeneity of anticardiolipin antibodies defined by the anticardiolipin cofactor. F Immunol 1992; 148: 3885-91.

12 McNeil H P, Simpson R J, Chesterman C N, Krilis S A. Antiphospholipid antibodies are directed against a complex antigen that induces a lipid-binding inhibitor of coagulation: $\beta 2$-glycoprotein 1 (apolipoprotein H). Proc Natl Acad Sci USA 1990; 87: 4120-4.

13 Galli M, Comfurius P, Maassen C, et al. Anticardiolipin antibodies (ACA) directed not to cardiolipin but to protein cofactor. Lancet 1990; 335: 1544-7.

14 Matsuura E, Igarashi Y, Fujimoto M, Ichikawa K, Koike T. Anticardiolipin cofactor(s) and differential diagnosis of autoimmune disease. Lancet 1990; 336: 177-8.

15 Hunt J E, McNeil H P, Morgan G J, Crameri R M, Krilis S A. A phospholipid- $\beta 2$-glycoprotein 1 complex in an antigen for anticardiolipin antibodies occurring in 1: 75-81. 
16 Watts $\mathrm{R}$, Williams W, Le Page S, et al. Analysis of autoantibody reactivity and common idiotype PR4 expression of myeloma proteins. F Autoimmun 1989; 2: 689-700.

17 Keeling D M, Wilson A J G, Mackie I J, et al. Lupus anticoagulant activity of some antiphospholipid antibodies against phospholipid bound $\beta 2$ glycoprotein-1. f Clin Pathol 1993; 46: 665-8.

18 Sutjita M, Hohmann A, Comacchio R, et al. A common anti-cardiolipin antibody in autoimmune disease: identification using a mouse monoclonal directed against a naturally occurring antiphospholipid antibody. Clin Exp Immunol 1989; 75: 211-6.

19 Brooks D A, Bradley J, Zola H. A differentiation antigen expressed selectively by a proportion of human blood cells: detection with a monoclonal antibody. Pathology 1982; 14: 5-11.

20 Sutjita M, Hohmann A, Comacchio $R$, et al. Polyspecific human and murine antibodies to diphtheria and tetanus toxoids and phospholipids. Clin Exp Immunol 1988; 73: 191-7.

21 Marrow W J W, Isenberg D A. Autoimmune rheumaic disease. Oxford: Blackwell Scientific Publications, 1987.

22 Casali P, Notkins A L. Probing the B cell repertoire with EBV: polyreactive antibodies and CD $5+\mathrm{B}$ lymphocytes. Ann Rev Immunol 1989; 7: 513-35.

23 Lafer E I, Rauch J, Andrzejewski D, et al. Polyspecific monoclonal lupus autoantibodies reactive with both polynucleotides and phospholipids. $\mathcal{F} \operatorname{Exp} M e d$ 1981; 153: 897-909.

24 Castello P B, Green F A. Reactivity patterns of human anticardiolipin and other antiphospholipid antibodies in syphilitic sera. Infect Immun 1986; 51: 771-5.

25 Rauch J, Janoff A S. Phospholipids in the hexagonal II phase is immunogenic: evidence for immunorecognition of nonbilayer lipid phases in vivo. Proc Natl Acad Sci USA 1990; 87: 4112-4.

26 Frampton G, Hicks J, Cameron J S. Significance of antiphospholipid antibodies in patients with lupus nephritis. Kidney Int 1991; 39: 1255-31.

27 Out H J, de Groot P G, Van Vliet M, et al. Antibodies to platelets in patients with anti-phospholipid antibodies. platel in patients with

28 Rauch J, Tennenbaum M, Janoff A S. Distinguishing plasma lupus anticoagulants from anti-factor antibodies using hexagonal (II) phase phospholipids. Thromb Haemostas 1989; 62: 892-6.

29 Love P E, Santoro S A. Antiphospholipid antibodies: Anticardiolipin and the lupus anticoagulant in SLE and non-SLE disorders. Ann Int Med 1990; 112: 682-98.

30 Hohmann A, Comacchio R, Boswarva V, et al. The $\mathrm{H}_{3}$ antiphospholipid idiotype is found in patients with systemic lupus erythematosus (SLE) but not in patients with syphilis. Clin Exp Immunol 1991; 86: 207-11.

31 Kalsi J, Ravirajan C T, Blanco-Favela F, et al. Analysis of three autoantibody idiotypes RT-6 Id, RT-72 Id and RT-84 Id. Autoimmunity 1993; 14 (suppl 1): 19. 